\title{
Diacronie
}

Studi di Storia Contemporanea

$N^{\circ} 24,4 \mid 2015$

Le dittature militari: fisionomia ed eredità politica

\section{Le poids des militaires et des clercs dans le pouvoir franquiste : un facteur de stabilité et de pérennité de la dictature?}

Justine Guitard

\section{(2) OpenEdition \\ Journals}

\section{Édition électronique}

URL : http://journals.openedition.org/diacronie/3820

DOI : 10.4000/diacronie.3820

ISSN : 2038-0925

Éditeur

Association culturelle Diacronie

Référence électronique

Justine Guitard, «Le poids des militaires et des clercs dans le pouvoir franquiste : un facteur de stabilité et de pérennité de la dictature? », Diacronie [En ligne], № 24, 4 | 2015, document 15, mis en ligne le 29 décembre 2015, consulté le 10 décembre 2020. URL : http://journals.openedition.org/ diacronie/3820 ; DOI : https://doi.org/10.4000/diacronie.3820 


\section{Diacronie}

\section{Le poids des militaires et des cleres dans le pouvoir franquiste: un facteur de stabilité et de pérennité de la dictature?}

Justine GUITARD *

En Espagne, le régime franquiste dure presque quarante ans (1939-1975). Il s'installe par la force des armes (Alzamiento) après une sanglante guerre civile revendiquée comme un acte héroïque, comme une croisade (Cruzada). Un général en profite pour se hisser au pouvoir suprême : les titres de Caudillo d'Espagne par la grâce de Dieu et de Généralissime des Armées de Terre, de Mer et de l'Air lui sont conférés. Le dictateur s'appuie sur l'Armée pour garantir l'ordre et sur l'Église pour inculquer la morale chrétienne dans tout le pays. Les deux clés de voûte du système lui assurent une stabilité et une pérennité jamais égalée dans l'histoire contemporaine de l'Espagne.

\section{Introduction}

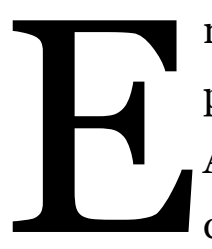

n Espagne, la désapprobation d'une situation politique par l'opinion publique donne quasi systématiquement lieu à une intervention de l'Armée. Après la Guerre d'Indépendance en 1814 et jusqu'à la tentative de coup d'État échouée en 1981 (plus connue sous le nom de 23-F), une cinquantaine de coups d'État et putschs se sont produits ${ }^{1}$. En 1820, le putsch du général Rafael de Riego permet de rétablir la Constitution; en 1840, le militaire Baldomero

\footnotetext{
${ }^{1}$ SECO SERRANO, Carlos, Militarismo y civilismo en la España contemporánea, Madrid, Instituto de Estudios Económicos, 1984, p. 13.
} 
Espartero se soulève et chasse la reine régente María Cristina; en 1854, dans le but de réformer l'Espagne, le général Leopoldo O’Donnell prend les armes; en 1874, Arsenio Martínez-Campos fait un coup d'État pour mettre un terme à la Ière République; en 1923, Miguel Primo de Rivera instaure une dictature qui est relayée par la dictablanda de Dámaso Berenguer. Le «pretorianismo español» est un fait: l'élite militaire exerce une forte influence dans la politique, en particulier aux XIX ${ }^{\text {ème }}$ et XXème $^{\text {siècles }}{ }^{2}$. À chaque fois, l'Armée est l'instigatrice des changements politiques parce qu'elle se veut détentrice exclusive du patriotisme. Et pour cause, les hauts dignitaires de l'Armée sont convaincus qu'ils sont les seuls à pouvoir rétablir la «vérité nationale», et, au fil des années, ils se sentent investis de l'obligation et du devoir de «salvar a España del bolchevismo y la barbarie africana»3. Les militaires au nationalisme exacerbé considèrent qu'ils sont les gardiens du destin de l'Espagne et qu'ils doivent intervenir pour défendre les intérêts de la patrie 4 . Au cours du XXème siècle, cette faraude croyance ne cesse de s'accroître parmi les officiers, et plus particulièrement parmi ceux qui se sont battus dans de dures conditions pendant les guerres coloniales marocaines, lesdits africanistes 5 .

Cependant que les réformes s'avèrent trop lentes, le mécontentement gronde sous la II ${ }^{\text {nde }}$ République en place depuis 1931. Les déséquilibres sociaux (la terre est répartie de manière inégalitaire et les ouvriers vivent dans des conditions de vie tout à fait misérables) et régionaux (le développement des régions est lui aussi inégal) posent problème ${ }^{6}$. Des affrontements entre propriétaires terriens et prolétaires, entre catholiques et anticléricaux, entre centralistes et régionalistes mettent en péril la jeune République en construction. Pour les forces antirépublicaines en présence, le communisme, la franc-maçonnerie et l'athéisme seraient les responsables de tous les maux du pays. C'est dans ce contexte qu'une coalition de militaires, d'hommes

2 Cfr. NÚÑEZ FLORENCIO, Rafael, Militarismo y antimilitarismo en España (1888-1906), Madrid, Consejo Superior de Investigaciones Científicas, 1990, pp. 18-19.

3 BOYD, Carolyn, La política pretoriana en el reinado de Alfonso XIII, Madrid, Alianza, 1990, p. 172.

4 MARTÍNEZ REVERTE, Jorge (coord.), Los militares españoles en la Segunda República, Madrid, Pablo Iglesias, 2012, pp. 7-40.

5 GIMÉNEZ MARTÍNEZ, Miguel Ángel, «El ejército de Franco: un gigante con pies de barro», in Passagens. Revista Internacional de História Política e Cultura Jurídica, 6, 3/2014, p. 442.

${ }^{6}$ Pour en savoir plus, voir CARR, Raymond, Estudios sobre la República y la Guerra Civil Española, Barcelona, Ariel, 1973; DEL REY REGUILLO, Fernando, ÁlVAREZ CHILLIDA, Gonzalo, GARCÍA FERNÁNDEZ, Hugo et al., Palabras como puños. La intransigencia política en la Segunda República española, Madrid, Tecnos, 2011; GIL PECHARROMÁN, Julio, La Segunda República Española, Madrid, Biblioteca Nueva, 2006; GONZÁLEZ CALLEJA, Eduardo, COBO ROMERO, Francisco, MARTÍNEZ RUS, Ana et. al., La Segunda República Española, Madrid, Pasado \& Presente, 2015; JULIÁ, Santos, Política en la Segunda República, Madrid, Ayer, 1995. 
politiques de droite et d'extrême droite conspire. Les Nationalistes se soulèvent le 18 juillet 1936; cette date marque le déclenchement de la guerre civile, particulièrement sanglante. Lorsque le conflit éclate, chacun doit prendre position dans l'un ou l'autre camp et se battre pour ses convictions7. Écartée du pouvoir et privée de ses atouts sous la République, l'Église se rallie immédiatement à la cause des Nationalistes afin de retrouver ses lettres de noblesse en Espagne. Cette guerre fratricide remportée par les Nationalistes dure près de quatre années; quatre années de misère où souffrance, peur et mort cohabitent.

Endéans les quatre années de chaos, un homme en profite pour se hisser au pouvoir suprême: il s'agit du général Francisco Franco Bahamonde, militaire de carrière, qui gravit tous les échelons de l'Armée jusqu'en 1939, année durant laquelle il devient Caudillo d'Espagne par la grâce de Dieu, comme l'écrivent ses hagiographes après la victoire. "Champion de la conservation sociale et de la tradition ${ }^{8}$ d'après les dires de l'historien français Bartolomé Bennassar, le franquisme s'ancre durablement grâce aux choix stratégiques du dictateur qui compose des gouvernements hétérogènes en fonction de la conjoncture nationale et internationale. En effet, militaires, phalangistes et clercs se partagent les postes de pouvoir du régime pendant quasiment quarante années (1939-1975). Ce partage se fait au sein même des trois familles institutionnelles du système franquiste, l'Armée, l’Église et la Phalange ${ }^{9}$. Mutatis mutandis, le Caudillo écarte une grande famille du pouvoir, parce qu'elle est lourdement discréditée par l'opinion publique internationale ${ }^{10}$. Restent alors l'Église et l'Armée, les deux grandes familles institutionnelles de poids dans la dictature. Mais quel est donc le rôle réel de ces deux institutions au sein du régime franquiste? En quoi la politisation des militaires et des clercs assure-t-elle la stabilité et la pérennité du régime? D’une part, nous analyserons l'appui et la légitimation du régime légués par les deux structures que sont

\footnotetext{
7 Deux camps s'affrontent: le camp des Nationalistes (ces insurgés sont principalement des militaires et des hommes politiques de droite et d'extrême droite) et le camp des Républicains (tous ceux restés fidèles à la République).

8 BENNASSAR, Bartolomé, Histoire des Espagnols: VI $-X X^{e}$ siècle, Paris, Robert Laffont, 1992, p. 835 .

9 TANGO, Cristina, L'Espagne: Franquisme, transition démocratique et intégration européenne (1939-2002), Genève, Institut européen de l'Université de Genève, 2006, p. 13, URL: < http://www.unige.ch/gsi/files/8314/o351/6379/tango.pdf > [consulté le 8 novembre 2013].

${ }^{10}$ Les phalangistes sont écartés du pouvoir après la Seconde Guerre mondiale à cause de leur germanophilie et de leur forte implication aux côtés de l'Axe entre autres. La Phalange est le parti unique de l'État qui joue le rôle d'appareil de contrôle et de domination politique et sociale, sans ne jamais disposer d'une autonomie. L'effervescence dans laquelle le parti est accueilli en 1939 s'effondre progressivement, et en 1945, il ne joue plus qu'un rôle subalterne (de propagande et de moyen de mobilisation des citoyens).
} 
l'Armée et l'Église ; et, d'autre part, nous étudierons les clés de voûte du système comme étant les garants de l'ordre et de la morale en Espagne.

\section{Appui et légitimation de la dictature}

L'Armée et l'Église exercent une prédominance dans la société espagnole des siècles durant ${ }^{11}$. Les deux institutions sont sans doute associées l'une à l'autre depuis deux épisodes majeurs qui projettent l'image de l'Espagne éternelle qui tient tant à cœur au général Franco : d'une part, la Reconquête (722-1492) lorsque les chevaliers chrétiens et les différents ordres de moines-soldats chassent les musulmans de la péninsule ibérique et, d'autre part, la Conquête de l'Amérique (à compter de 1492) qui est justifiée au nom de l'évangélisation des peuples indigènes. L’Armée et l'Église agissent côte à côte, l'une servant l'intérêt de l'autre et vice versa. Au fil des siècles, l'Armée assure la sécurité du système politique en place et recourt à des coups d'État pour changer de gouvernement quand elle l'estime opportun. L'Église, quant à elle, justifie et légitime systématiquement le pouvoir en place, et ce n'est d'ailleurs pas anodin si l'on parle de monarchie de droit divin comme pour valider le bien-fondé de la puissance du suzerain.

Sous la II ${ }^{\text {nde }}$ République, la volonté des élus est de moderniser le pays en passant par une démocratisation et une laïcisation profonde du système espagnol. Les Républicains s'opposent vivement à l'oligarchie et à l'Église, qui perdent alors bon nombre de leurs privilèges. L'Armée et l'Église sont ébranlées par la République puisque l'on programme de les réformer considérablement ${ }^{12}$. L'on prévoit la diminution des effectifs de l'Armée ${ }^{13}$, que l'on veut transformer en unique défenseuse de la démocratie, ainsi que la sécularisation de la société avec pour volonté la limitation de l'influence religieuse en Espagne ${ }^{14}$.

${ }_{11}$ BAQUER, Miguel Alonso, El ejército en la sociedad española, Madrid, Ediciones del Movimiento, 1971; BOWEN, Wayne H., Spain since the Reconquista, Oxford, Oxford University Press, 2013; CALLAHAN, William J., The Catholic Church in Spain, 1875-1998, Washington D.C., The Catholic University of America Press, 2000; LANNON, Frances, Privilege, Persecution, and Prophecy: The Catholic Church in Spain 1875-1975, Oxford, Clarendon Press, 1987.

${ }_{12}$ NIN I PÉREZ, Andreu, La revolución española: 1930-1937, Barcelona, El Viejo Topo, 2008, pp. 234-237.

${ }^{13}$ La promulgation de la Ley de retiro de la oficialidad (1931) sert les intérêts de la République. En effet, les militaires se voient contraints de jurer fidélité à la jeune République. S’ils ne le font pas, ils doivent quitter l'Armée. La République ferme également la Academia militar de Zaragoza jugée traditionnaliste et démodée. Des tensions se ressentent au sein de l'Armée au moment de ces réformes: elle les considère comme une véritable agression à la tradition militaire.

${ }^{14}$ La République déclare la non confessionnalité de la patrie. L'État prône la liberté de culte, le mariage civil et le divorce sont désormais autorisés. L'enseignement est retiré des mains des 
Ces deux institutions qui sont des forces contre-révolutionnaires, très traditionnalistes, entendent lutter contre les réformes et la modernisation voulues par la République ${ }^{15}$. L'attitude réactionnaire de l'Armée et de l'Église les rapproche des idéaux des partis de droite et du fascisme naissant.

\subsection{L'Alzamiento}

Préparée de longue date, l'Armée se soulève le 18 juillet 1936: c'est l'Alzamiento nacional $^{16}$. La volonté de l'Armée est de rétablir l'unité nationale et l'ordre social. À la tête des insurgés, l'on retrouve plusieurs officiers dont certains sont africanistes: Francisco Franco, Emilio Mola, Miguel Cabanellas et Gonzalo Queipo de Llano. Le coup d'État qui devait être rapide est partiellement mis en échec: une guerre totale se déclenche alors. Le peuple s'arme et tente de résister à l'Armée. Certaines régions tombent rapidement entre les mains des Nationalistes comme la Navarre, la Galice, une grande partie de l'Andalousie... tandis que d'autres résistent dans une initiative de fidélité à la République. Madrid, Barcelone et Valence restent républicaines. Le pays est divisé en deux camps: les Nationalistes occupent la moitié du territoire, les Républicains l'autre moitié. Au début du conflit, les forces semblent à peu près égales, chaque camp disposant d'environ 500.000 hommes. Mais l'organisation des Nationalistes qui reçoit les directives d'officiers bien entraînés, l'aide militaire et économique reçue de l'Allemagne, de l'Italie et du Portugal, et les offensives qu'ils savent bien échafauder font que l'Armée progresse cependant que les Républicains semblent déstructurés car dépourvus d'officiers et de commandements clairs. Dans la zone nationale, le général Franco reçoit le titre de Généralissime et devient le Chef du Gouvernement de l'État le $1^{\text {er }}$ octobre 1936. Malgré l'aide des Soviétiques d'une part, et des Brigades Internationales ${ }^{17}$ d'autre part, la zone républicaine est envahie

religieux: l'école devient laïque. Toutes ces mesures provoquent une radicalisation de la situation et une soif de vengeance de la part des clercs.

15 PRESTON, Paul, La destrucción de la democracia en España. Reforma, reacción y revolución en la Segunda República, Barcelona, Grijalbo-Mondadori, 2011.

${ }^{16}$ L'Alzamiento nacional, ou le soulèvement national, est le nom donné par les Nationalistes à la date du 18 juillet 1936. Jusqu'en 1977, cette date est célébrée en Espagne en mémoire du soulèvement armé contre ce que les franquistes appellent la tyrannie rouge: c'est la fête nationale.

${ }_{17}$ Les Brigades Internationales viennent en aide aux Républicains. Il s'agit de volontaires antifascistes de pays différents. Communistes, marxistes, anarchistes et socialistes du monde entier s'engagent dans des convois pour l'Espagne afin d'appuyer la défense menée par les Républicains et de conserver la démocratie en Espagne. Entre 30 ooo et 35000 hommes de divers pays se sont battus aux côtés des Républicains entre 1936 et 1939. Cfr. DEMIDJUK, Stanislav, SKOUTELSKY, Rémi, Nouveaux regards sur les Brigades internationales: Espagne 1939-1939, Montpellier, Indigène, 2010. 
progressivement jusqu'aux prises ultimes de Barcelone, de Madrid et d'Alicante. Le samedi $1^{\text {er }}$ avril 1939, un communiqué du Caudillo est diffusé par le poste de RadioNacional: «En el día de hoy, cautivo y desarmado el Ejército rojo, han alcanzado las tropas Nacionales sus últimos objetivos militares. LA GUERRA HA TERMINADO» ${ }^{18}$.

La longue et difficile victoire des troupes franquistes confère au général Franco tous les pouvoirs: il est Généralissime, Caudillo d'Espagne par la grâce de Dieu, Chef de l'État et Président du Conseil des ministres ${ }^{19}$. Au cours des presque quatre années de guerre, l'Armée porte donc au pouvoir suprême un homme, un général qui assure désormais en Espagne le rôle de Chef. La dictature qui s'ensuit doit absolument tout à cette bataille militaire, engagée pour lutter contre la décadence du pays due au communisme, à la franc-maçonnerie et à l'athéisme qui en sont, selon les dires des Nationalistes, les uniques responsables.

\subsection{La Croisade}

L'Église soutient fortement le coup d'État en se ralliant aux Nationalistes dès le 18 juillet $1936^{20}$. Les membres du clergé participent activement à la guerre civile et jouent un rôle déterminant dans le processus d'homogénéisation idéologique des troupes nationalistes ${ }^{21}$. Pour la hiérarchie catholique, qui signe en 1937 la «Carta colectiva de los obispos españoles a los de todo el mundo con motivo de la guerra de España»22, la guerre civile n'est rien d'autre qu'une «Cruzada por la religión, por la patria y por la civilización cristiana» ${ }^{23}$ comme le clame haut et fort l'évêque de Salamanque, Enrique Plá y Deniel, dans sa lettre pastorale «Las dos ciudades», datant du 30 septembre 1936. Le terme de croisade n'est en rien anodin: il sert à justifier l'entreprise nationaliste. Le fort anticléricalisme républicain qui anime la société depuis 1931 représente un réel

\footnotetext{
${ }_{18}$ RUEDA, Andrés, Franco, el ascenso al poder de un dictador, Madrid, Nowtilus, 2013, p. 265. 19 BAQUER, Miguel Alonso, «El papel de los militares en la configuración del franquismo», in La Arbolafia: Revista de Humanidades y Cultura, 1, 1/2014, , pp. 35-47, p. 42, URL: < http://www.albolafia.com/trab/Alb-Doss-001.BAQUER.pdf > [consulté le 3 août 2015]. ${ }^{20}$ Les relations entre l'Armée et l'Église se sont tissées au fil des siècles et remontent aux temps immémoriaux de la Reconquête et de la Conquête de l'Amérique, comme nous l'avons évoqué un peu plus tôt.

${ }^{21}$ MAURICE, Jacques, SERRANO, Carlos, L'Espagne au XXe siècle, Paris, Hachette Supérieur, 1995, pp. 141-142.

${ }_{22}$ Cette lettre rédigée par le cardinal Isidro Gomá stipule le soutien de l'Église aux troupes nationalistes. Signée et publiée le $1^{\text {er }}$ juillet 1937 à Pampelune, elle est endossée par quarantetrois évêques et diffusée largement pour montrer l'authentique engagement de l'Église et contrer l'hostilité de la presse étrangère qui ne cesse d'associer le clergé espagnol au principal instigateur de la guerre civile.

23 PLÁ Y DENIEL, Enrique, «El triunfo de la Ciudad de Dios y Resurrección de España», in Boletín Oficial del Obispado de Salamanca, 8-28 mai 1939, p. 182.
} 
danger pour l'Église; aussi le ralliement à la cause nationaliste est tout à fait naturel et s’inscrit dans une lutte contre la sécularisation de la société espagnole.

El elemento religioso fue fundamental una vez iniciada la guerra, ya que sirvió para dar al levantamiento militar la justificación que necesitaba, tanto de cara al interior como al exterior, para lavar la imagen de perturbadores del orden legalmente establecido que tenían. Así, gracias al apoyo de la Iglesia, al golpe militar se le dio el sentido de cruzada religiosa, el cual mutaría hacia el de reserva espiritual de occidente una vez que la guerra terminase y se impusiera definitivamente el régimen franquista ${ }^{24}$.

Se joignent aussi à la bataille des membres de divers ordres, jésuites et dominicains essentiellement, et du clergé séculier , comme Joaquín Azpiazu , Constantino Bayle, Aniceto Castro Albarán ou encore Ignacio González Menéndez-Reiga. Tous contribuent finalement, de près ou de loin, à la mise en place du régime franquiste en appuyant l'Armée et en légitimant la prise des armes pour sauver l'Espagne du marasme ambiant. L'Église promeut une image de sainteté et de salut de l'âme espagnole pendant la guerre civile. Pour chaque victoire nationaliste, il y a une osmose entre l'Église et l'Armée. Lorsque Luis Palacios Bañuelos raconte les victoires successives du camp des insurgés, il décrit des cérémonies entre militaires et religieux particulièrement grandiloquentes. Ces liturgies sont présidées par des généraux ou des maires qui, entourés de drapeaux, écoutent l'hymne national au moment de la consécration. Il explique que la ferveur religieuse se mêle à la ferveur guerrière ${ }^{25}$. Prenons pour exemple la prise de Gérone le 4 février 1939: les habitants acclament les troupes et leur offrent des branches de laurier comme si précisément elles étaient venues les libérer. Le général Franco est reçu comme un sauveur, comme un libérateur. Sara Nuñez de Prado compare cet épisode à l'entrée de Jésus de Nazareth à Jérusalem, accueilli par les Juifs sous une salve d'applaudissements ${ }^{26}$. Cette interpénétration entre le religieux et le militaire porte un nom : le national-catholicisme ${ }^{27}$.

${ }^{24}$ NUÑEZ DE PRADO, Sara, «El papel de la Iglesia en la configuración del franquismo», in $L a$ Arbolafia: Revista de Humanidades y Cultura, 1, 1/2014, p. 97, URL: < http://www.albolafia.com/trab/Alb-Doss-0o1.NUNEZ_DE_PRADO.pdf > [consulté le 3 août 2015].

25 PALACIOS BAÑUElOS, Luis, Historia de España. El franquismo y la España de la posguerra, vol. 1, Madrid, Club Internacional del Libro, 2007, p. 46.

${ }^{26}$ NUÑEZ DE PRADO, Sara, «El papel de la Iglesia en la configuración del franquismo», op. cit., p. 101.

${ }_{27}$ GALLO, Max, Histoire de l'Espagne franquiste, vol. 1, Verviers, Marabout Université, 1975, pp. 154-155. 
El clima nacional-católico había llegado al paroxismo con la liberación de todo el territorio nacional. El Cardenal Gomá investía a Franco como Caudillo en la iglesia de Santa Bárbara de Madrid el 20 de mayo de 1939. Franco proclamaba: "nuestra lucha tuvo caracteres de Cruzada". Y ofrecía al Cardenal Gomá "la espada de la victoria". Y éste se felicitaba "por la terminación de la Cruzada, en que fueron vencidos el comunismo ateo y los seculares enemigos de la España inmortal”28.

Ce sauveur au sens religieux du mot, ce libérateur au sens militaire du terme, n'est autre qu'un général espagnol. Si Francisco Franco cumule des titres religieux (Caudillo par la grâce de Dieu) et militaires (Généralissime des Armées de Terre, de Mer et de l'Air) à la fois ${ }^{29}$, ce n'est pas un hasard. Il se veut l'élu, celui qui rallie à sa cause le peuple espagnol. Derrière lui, deux grandes familles institutionnelles l'appuient et le légitiment. Elles vont être pendant toute la durée du franquisme les garantes de l'ordre (en ce qui concerne l'Armée) et de la morale (dans le cas de l’Église). Le général Franco est sûr de ces deux institutions parce qu'«elles lui suffisent pour tenir le pays, l'encadrer»30. La dictature peut ainsi s'installer pour durer, ses jalons semblent solides.

\section{Les garants de l'ordre et de la morale}

Les deux grandes familles institutionnelles que sont l'Armée et l'Église jouent entre 1939 et 1975 le rôle de garde fou du régime, tout en équilibrant le pouvoir et en le stabilisant. Effectivement, l'ensemble des forces militaires espagnoles constitue le bras armé du régime et la colonne vertébrale de son système politique. Elle gère l'ordre public en réprimant durement le moindre affront fait au franquisme et elle fait partie intégrante du gouvernement politique dès la naissance du « Nouvel État ». L’Église, quant à elle, constitue bien le deuxième pilier du régime : « elle joue le rôle d'appui moral et [de] toit idéologique de la dictature »31. Elle est également impliquée politiquement puisqu'elle dirige l'éducation d'une main de fer, qu'elle intervient dans le

\footnotetext{
${ }_{28}^{28}$ PÉREZ AGOTE, Alfonso, «Sociología histórica del nacional-catolicismo español», in Historia Contemporánea, 26, 2003, pp. 207-237, pp. 220-221, URL:

< http://www.ehu.eus/ojs/index.php/HC/article/viewFile/5445/5299 > [consulté le 10 décembre 2015].

29 Voir aussi BACHOUD, Andrée, Franco ou la réussite d'un homme ordinaire, Paris, Fayard, 1997; PRESTON, Paul, Franco, Caudillo de España, Barcelona, Grijalbo, 2002; ZENOBI, Laura, La construcción del mito de Franco. De jefe de la legión a Caudillo de España, Madrid, Cátedra, 2011.

30 GALLO, Max, op. cit., p. 92.

${ }^{31}$ TANGO, Cristina, op. cit., p. 13.
} 
domaine de la presse et qu'elle forge durablement l'identité national-catholique de l'Espagne. L’Armée et l'Église sont indéniablement les clés de voûte du système.

\subsection{La colonne vertébrale du régime: l'Armée}

Pendant l'été 1936, un décret de la Junta de Defensa Nacional, qui assumait par ailleurs la direction de la zone soulevée avant que ne soient conférés au général Franco tous les pouvoirs, affirme que l'Armée est le cerveau, le cœur et le bras du soulèvement national et qu'elle conservera tous ses pouvoirs jusqu'au rétablissement de la «paz auténtica, de la disciplina efectiva, del orden absoluto y del decoro nacional» ${ }^{2}$. Une fois la guerre civile achevée, l'Armée devient la «columna vertebral de la Patria» et le «depósito moral de las más nobles y enérgicas virtudes»33 de la société espagnole. Et le régime ne lésine pas sur les dépenses pour financer l'Armée qui dispose peu ou prou de la moitié du budget de l'État, et qui s'élèvent même à 53,7\% du budget total en $1943^{34}$, ce qui est tout à fait colossal. En contrepartie, l'Armée a pour mission de défendre le régime. Toute une série de lois vient fixer cette volonté du système d'éliminer toute opposition afin de perdurer, et c'est l'Armée qui veille à leur bonne mise en application. Le 9 février 1939, la promulgation de la Ley de Responsabilidades Políticas donne le ton puisqu'elle est rétroactive et s'applique à tous ceux qui ont participé à la création du Front Populaire en 1934 et qui ont collaboré avec lui d'une manière ou d'une autre. Le 23 septembre de la même année, une loi amnistie tous ceux qui ont combattu aux côtés des Nationalistes. Le $1^{\mathrm{er}}$ mars 1940, la Ley de Represión de la Masonería y del Comunismo permet de poursuivre ceux qui, de près ou de loin, développent des idées contre la patrie, la religion, la paix sociale ou les institutions. Enfin, le 29 mars 1941, la Ley de Seguridad del Estado sanctionne toute tentative de sédition susceptible de mettre en péril l'harmonie sociale de l'État. Selon Santos Juliá, ces lois constituent les «instrumentos de la legalidad represora»35.

Dans ce contexte, la peur rode... et c'est la «terreur blanche» ${ }^{6}$ qui s'abat sur tout le pays. Elle est organisée par l'Armée pour assurer le maintien de l'ordre public. La

${ }^{2}$ DÍAZ-PLAJA, Fernando, La España política del siglo XX en sus fotografías y documentos, vol. 3, Barcelona, Plaza \& Janés, 1970, p. 35.

33 El Movimiento Nacional, las Leyes Fundamentales y el sistema de instituciones (El pensamiento de Franco y la configuración del Régimen político español), Madrid, Ediciones del Movimiento, 1973, p. 251.

34 BUSQUETS, Julio, CARDONA, Gabriel, Unas fuerzas armadas para el Movimiento, in SINOVA, Justino, Historia del franquismo, vol. 1, Madrid, Diario 16, 1984, p. 162.

35 JULIÁ, Santos, Un siglo de España: política y sociedad, Madrid, Marcial Pons, 1999, p. 146.

${ }^{36}$ Le terme de «terreur blanche» est utilisé pour décrire une période d'excessive répression menée par des conservateurs à l'encontre de dissidents révolutionnaires. Généralement, elle suit 
Guardia Civil sévit dans les espaces ruraux et la Policía Armada frappe dans les zones urbaines. Les procès sont ensuite sous la responsabilité des tribunaux militaires ${ }^{37}$. Le Consejo Supremo de Justicia Militar est un organe à la fois administratif et judiciaire à l'intérieur de l'Armée. Il décide des sentences tout seul et ne fait aucun cas des circonstances propres à chacun. Les jugements sont rapides et délibérément tranchés. Pour la période 1939-1945 $5^{38}$, l'épuration des ennemis politiques du régime est réelle: il faut compter entre 600 ooo et 700000 prisonniers politiques et entre 100000 et 200 ooo personnes exécutées ou mortes dans les geôles franquistes39. Rien que dans la capitale espagnole, à Madrid, près de 100 ooo Républicains sont exécutés entre mars 1939 et mars $1940^{40}$. En matière de répression, le système franquiste est l'un des plus cruels de l'histoire contemporaine. «On épure, on dénonce, on arrête, on torture parfois, on fusille»41. Si l'Armée franquiste s'est façonnée en «machine à condamner»42, c'est que le régime craint d'être mis en difficulté par l'opposition.

L'Armée est omniprésente puisque c'est elle qui exécute les ordres: elle surveille tous les Espagnols, elle les suspecte tous, sans la moindre exception. De multiples inspecteurs en civils sont aussi placés dans les lieux publics pour scruter la population et déceler tout propos injurieux à l'encontre du régime. L'Espagne entière est en libertad vigilada. Le régime ne s'assouplit pas malgré le temps, et dans la décennie 1960, les grèves universitaires et les tensions dans le monde ouvrier sont durement réprimées. Pour faire face à ces contestations, le système met en place des organismes d'espionnage et d'infiltration. Naissent entre autres le Servicio de Información del Ejército et le Servicio Central de Documentación de la Presidencia del Gobierno43. L'un permet de réprimer les derniers Républicains encore présents à l'intérieur du pays et de gérer les informations pour sanctionner tous ceux qui peuvent être considérés comme déloyaux ou hostiles au général Franco; l'autre privilégie l'espionnage de toutes les personnes qui s'opposent résolument au régime franquiste notamment dans les

une tentative insurrectionnelle ou une forte opposition à cette dernière. Ce terme s'applique notamment à la guerre civile et à la sombre après guerre qui sont incontestablement des périodes de «terreur blanche» en Espagne.

37 PAYNE, Stanley, El régimen de Franco, 1939-1975, Madrid, Alianza Editorial, 1986, p. 388.

38 Période durant laquelle la répression est sans doute la plus systématique et la plus forte, même si elle se poursuit jusqu'en 1975. Après 1945, la répression, sans s'assouplir réellement, se produit de manière moins méthodique.

39 MAURICE, Jacques, SERRANO, Carlos, op. cit., pp. 35-49.

${ }^{\circ}$ GALLO, Max, op. cit., p. 76.

${ }^{41}$ Ibidem, p. 73.

42 Ibidem, p. 78.

43 Le Servicio Central de Documentación de la Presidencia del Gobierno (SECED) est créé par le bras droit de Francisco Franco, Luis Carrero Blanco, en 1972. Il sert à contrer les mouvements contestataires des étudiants et des ouvriers. Le service d'espionnage SECED est considéré comme le plus efficace de tous sous le franquisme. 
manifestations, dans les grèves ou encore dans les affronts avec la police. Ces organismes sont mis en place au sein de l'Armée, sont commandés par des officiers et sont exécutés par des militaires. En outre, à l’intérieur de la Policía Armada, la Brigada de Investigación Social lutte contre les délits politiques. Cette brigade est spécialisée dans les écoutes téléphoniques, dans le contrôle de la correspondance, et détient les inculpés indéfiniment. À travers les armes des militaires, le régime cherche l'apathie et la démobilisation totale de la population.

En 1958, une loi asserte que les Armées de Terre, de Mer et de l'Air d'Espagne constituent la «garantía de su seguridad y expresión de las virtudes heróicas»44. Il s'agit de la Ley de Principios del Movimiento Nacional. Plus tard, en 1967, la Ley Orgánica del Estado renchérit que l'Armée «garantiza la unidad e independencia de la Patria, la integridad de sus territorios, la seguridad nacional y la defensa del orden institucional»45. Toutes ces lois permettent à l'Armée d'acquérir une place de choix et d'être perçue aux yeux de tous comme l'élément indispensable au bon fonctionnement de la société espagnole.

Les militaires présents dans les différents gouvernements de Francisco Franco n'y sont pas étrangers. En effet, la présence des militaires dans les Ministères, en particulier dans les domaines de politique extérieure et d'ordre public, est indéniable. Miguel Ángel Giménez Martínez parle d'une politisation active des dirigeants militaires qui jouent plus le rôle de politiques que de militaires et d'une politisation passive de l'institution en elle-même, ce qui revient à dire que le franquisme est un «régimen bajo tutela militar» dans lequel «el Ejercito no gobierna por sí m ismo, pero desempeña un papel muy importante en la vida política»46. Pour chiffrer ces dires, il faut savoir que jusqu'en 1945, environ 30\% des postes de ministres sont occupés par des officiers de l'Armée, 35\% des postes importants du Movimiento 47 sont également entre les mains des militaires, 90\% des postes de la Présidence du Gouvernement sont attribués à des dignitaires de l'Armée, 70\% des postes du Secrétariat de l'Ordre Public sont aussi investis par des membres de l'Armée ${ }^{48}$. Dans les différents gouvernements successifs du

44 GIMÉNEZ MARTÍNEZ, Miguel Ángel, «El ejército de Franco: un gigante con pies de barro», cit., p. 447.

45 Ibidem, p. 447.

46 DUVERGER, Maurice, Instituciones políticas y derecho constitucional, Barcelona, Ariel, 1970 , p. 384.

47 Le Movimiento Nacional, le Mouvement National, est le seul parti politique officiel de l'État franquiste. Il est issu de la fusion entre la Falange Española Tradicionalista (FET) et les Juntas de Ofensiva Nacional Sindicalista (JONS). Il est également dénommé la Falange Española Tradicionalista y de las Juntas de Ofensiva Nacional Sindicalista (FET y de las JONS).

48 VIVER PI-SUNYER, Carlos, El personal político de Franco (1936-1945), Barcelona, Vicens Vives, 1978, pp. 70-72. 
Caudillo, parmi les 116 ministres qui se succèdent, 32 appartiennent à l'Armée. Si pendant la guerre civile et les premières années du régime, les officiers peuvent occuper tout type de poste ministériel et jouent un rôle militaire en s'occupant aussi de la gestion des sections militaires et des documents de grande importance politique tels que Francisco Gómez -Jordana aux Affaires Étrangères , Severiano Martínez Anido à l'Intérieur, Juan Antonio Suanzes à l'Industrie ，Agustín Mun oz Grandes 49 au Secrétariat du Movimiento ou encore Luis Carrero Blanco à la Présidence; ensuite, les officiers occupent prioritairement des postes dans les domaines de politique extérieure et d'ordre public, comme nous avons pu le signaler antérieurement. Dans les années 1950 et 1960, des ministres militaires occupent encore des postes de tout type mais ils sont moins nombreux; par exemple, Jorge Vigón est investi aux Travaux Publics, Camilo Alonso Vega est nommé ministre du Gouvernement. À la fin du franquisme, dans les années 1970, les officiers de l'Armée sont uniquement investis dans les domaines militaires (Ministère de l'Armée, de la Marine et de l'Air). Avec la consolidation du régime, les militaires semblent moins nombreux dans les Ministères. L'on peut aisément constater que le général Franco s'entoure de militaires sans véritable idéologie, de compagnons d'armes ou d'amis personnels afin que sa place ne soit jamais remise en question. De ce fait, l'attitude générale des militaires est l'authentique fidélité au dictateur. Mais six autres raisons expliquant la fidélité des militaires à l'égard du régime sont évoquées par Álvaro Soto Carmona. Pour lui, outre la loyauté au général Franco, il y a aussi l'hostilité envers la démocratie, l'attachement à l'ordre public, la croyance en la nécessité de la guerre civile, la conviction que l'Espagne est un État confessionnel par essence, l'image traditionnelle et autoritaire de la vie et de la société et le fort nationalisme espagnol50.

L’Armée est bien la colonne vertébrale du régime. Présente sur tout le territoire espagnol pour anéantir toute rébellion et dans les postes ministériels importants, elle pérennise le pouvoir du dictateur à travers son régime. L’Armée est sans nul doute un instrument important de répression mais, au fil des années, elle se transforme aussi en barrière contre le progrès social et le changement politique. Miguel Ángel Giménez

49 Ce personnage qui est relié à l'appareil militaire fait partie des autorités politiques du franquisme. Pendant la guerre civile, il joue un rôle prépondérant en prenant notamment la Catalogne aux Républicains. Il occupe ensuite des postes civils (secrétaire du Movimiento, ministre et vice-Président du Gouvernement) et militaires (capitaine général de l'Armée, Chef d'État Major) importants qui font de lui une personnalité incontournable de la dictature franquiste. Voir TOGORES, Luis E., Muñoz Grandes: héroe de Marruecos, general de la División Azul, Madrid, La esfera de los libros, 2007. $5^{\circ}$ SOTO CARMONA, Álvaro, Militares en la política en la España franquista, in PUELL DE LA VILA, Fernando, ALDA MEJÍAS, Sonia, Los ejércitos del franquismo (1939-1975), Madrid, Instituto Universitario General Mellado UNED, 2010, p. 369. 
Martínez ajoute par ailleurs que, contrairement à d'autres institutions a priori réactionnaires qui évoluent au rythme des changements économiques et sociaux, l'Armée campe sur ses positions et finit par s'éloigner de la volonté du peuple, et même s'en isoler ${ }^{1}$.

\subsection{Le pilier de la dictature: l'Église}

Le franquisme souhaite une restauration de l'ordre traditionnel. La croissante influence de l'Église dans la société espagnole passe par une «recatholisation» du système: à la destruction des normes et pratiques laïques de la République s'ajoute la remise en place du vieil ordre clérical. Dès 1938 (en pleine guerre civile), la loi du mariage civil est abrogée et l'on ne reconnaît plus les mariages qui n'ont pas été célébrés à l’Église. Les divorces et les avortements sont désormais interdits. Dès 1939, le Caudillo impose une forme de moralisation de la société espagnole dans un sens catholique et traditionnel; cela dans le but de chasser la prétendue immoralité républicaine. La fusion entre l'idéologie nationale et le catholicisme s'opère depuis la guerre civile, la notion de national-catholicisme est plus importante que jamais. En 1941, le gouvernement espagnol et le Saint-Siège signent une convention à Madrid qui implique la signature future d'un nouveau Concordat (le précédent de 1851 était caduc depuis 1931 et l'instauration de la République) dans l'optique de restaurer l'influence catholique sur le territoire espagnol. De nombreux chercheurs considèrent que l'effervescence religieuse qui anime le pays est poignante et en pleine expansion ${ }^{52}$. En effet, la présence aux messes semble toujours plus importante et systématique, la construction de séminaires et la reconstruction d'églises ainsi que de couvents qui sont impulsées par la Acción Católica Española, organisation de laïcs dont l'objectif principal est de collaborer avec l'Église dans des missions apostoliques, sont nombreuses. Alfonso Pérez Agote fait d'ailleurs remarquer que la population se sent presque obligée de s'investir dans la pratique religieuse «cómo para protegerse de eventuales acusaciones de actividades políticas anteriores»53.

${ }^{51}$ GIMÉNEZ MARTÍNEZ, Miguel Ángel, «El ejército de Franco: un gigante con pies de barro», cit., p. 442.

52 BOTTI, Alfonso, Cielo y dinero, El nacional-catolicismo en España (1881-1975), Madrid, Alianza Editorial, 1992; CASANOVA, Julián, La Iglesia de Franco, Madrid, Temas de Hoy, 2001; GÓMEZ PÉREZ, Rafael, El franquismo y la Iglesia, Madrid, Rialp, 1986; MARTÍ, Casimir, Iglesia y comunidad política, Salamanca, Universidad Pontificia, 1974; PÉREZ AGOTE, Alfonso, «Sociología histórica del nacional-catolicismo español», cit.

53 PÉREZ AGOTE, Alfonso, «Sociología histórica del nacional-catolicismo español», cit., p. 221. 
Voici donc venu le temps des enterrements mystiques au nombre abondant de clercs, des célébrations religieuses traditionnelles, des innombrables baptêmes d'enfants et d'adultes, des inconditionnelles processions à l'effigie du Christ, de la condamnation de certaines manifestations récréatives contraires à la morale (le carnaval en est un exemple), de la censure morale dans le cinéma, de la suppression de la prostitution non réglementée, de la séparation des sexes dans les piscines, de la réglementation des bals et de la surveillance extrême des spectacles. De surcroît, José María Piñol ajoute que l'on ne peut compter les messes à la campagne, les cérémonies organisées pour la Semaine Sainte et le Carême, les pèlerinages massifs de la Acción Católica Española, drapeaux déployés de Saint-Jacques-de-Compostelle et du Pilar de Saragosse, les événements religieux orchestrés par le Frente de Juventudes et la Sección Femenina54 du Movimiento Nacional55, «instrumento clave para organizar a los partidarios del régimen, [...] encuadrar y controlar a la sociedad civil a través de sus órganos dependientes»56. L’idéologie réactionnaire, le rejet de la modernité, la nostalgie du grand Empire des Rois Catholiques, l'idéal corporatif sont bien des éléments qui justifient cette effervescence religieuse57. En 1945, le sixième article du Fuero de los españoles, charte de 1945 instaurant toute une série de droits, de «libertés» et de devoirs pour le peuple espagnol et faisant partie des Leyes Fundamentales del franquismo, asserte la reconnaissance de l'Église.

La profesión y práctica de la Religión Católica, que es la del Estado Español, gozará de la protección oficial. Nadie será molestado por sus creencias religiosas ni en el ejercicio privado de su culto. No se permitirán otras ceremonias ni manifestaciones externas que las de la Religión Católica ${ }^{8}$.

\footnotetext{
54 Le Frente de Juventudes et la Sección Femenina sont des branches du Movimiento Nacional. Le Frente de Juventudes est créé en 1940 et sert à l'encadrement et à l'endoctrinement politique des jeunes espagnols. La Sección Femenina est tout simplement la branche féminine du parti, créée en 1934 et dirigée par Pilar Primo de Rivera y Sáenz de Heredia.

55 PIÑOL, José María, La transición democrática de la Iglesia católica española, Madrid, Trotta, 1999, p. 110.

${ }^{56}$ PAYNE, Stanley, El primer franquismo. Los años de la autarquía, Madrid, Temas de Hoy, 1997, p. 10.

57 Voir LÓPEZ GALLEGO, María Silva, La difícil relación de la Iglesia y la Organización Sindical Española durante el primer franquismo: la creación de la Asesoría Eclesiástica de Sindicatos (1944-1959), Madrid, Instituto de Historia. Consejo Superior de Investigaciones Científicas, 2004.

${ }^{5}$ Boletín Oficial del Estado, 199, 18 juillet 1945, pp. 358-36o, URL:

< http://www.boe.es/datos/pdfs/BOE/1945/199/A00358-00360.pdf > [consulté le $1^{\text {er }}$ août 2015].
} 
Une véritable symbiose s'observe «entre el catolicismo, el franquismo y España como nación, de tal manera que conformaron un todo inseparable e indivisible»59. La religion catholique est l'essence de l'Espagne, et le franquisme incarne l'«espagnolité». En protégeant l'Église, le régime se sert de l'instrumentalisation politique de la religion qui utilise des mites populaires, des symboles catholiques de l'histoire du pays «para ofrecer una imagen de continuidad con el pasado»6o. Le régime s'appuie incontestablement sur cette propagande ecclésiastique: le champ de l'information est investi par l'Église. Les journaux d'obédience catholique «Diario Ya», «La Gaceta del Norte» et «El Correo Español-El Pueblo Vasco» couvrent l'intégralité du territoire espagnol, et sont aussi relayés par des revues contrôlées par le clergé comme «Ecclesia», «La Hoja Dominical», «Signo», «Trampolín», «Impulso», «Alba de Juventud», «Volad», «Para Nosotras», etc. Les revues sont tirées à plus de 5.600.000 exemplaires et représentent quasiment $70 \%$ de l'ensemble des tirages, toutes revues confondues $^{61}$. Toutes ces publications permettent une large diffusion de la morale catholique, disséminée quotidiennement et de manière presque naturelle. La censure se charge d'éradiquer tout propos contraire à la morale ou susceptible de tâcher la «salud espiritual de los españoles» ${ }^{62}$. Après 1945 , le concept de national-catholicisme se renforce et prend davantage d'ampleur. Ceci s'explique par l'éviction progressive des phalangistes depuis le décret d'unification de 1937, et après la défaite définitive de

59 NUÑEZ DE PRADO, Sara, «El papel de la Iglesia en la configuración del franquismo», op. cit., p. 100.

60 MORENO SECO, Mónica, "Creencias religiosas y política en la dictadura franquista», in Pasado y Memoria, 1/2002, p. 20.

${ }^{61}$ BENNASSAR, Bartolomé, op. cit., p. 855.

${ }^{62}$ NUÑEZ DE PRADO, Sara, «El papel de la Iglesia en la configuración del franquismo», op. cit., p. 111. 
l'Allemagne le 8 mai 1945, jour où le III ${ }^{\text {ème }}$ Reich capitule définitivement ${ }^{63}$. Seule l'Église peut alors servir les intérêts de l'Espagne à l'étranger. Le général Franco en est bien conscient et souhaite sortir de l'ostracisme qui caractérise l'Espagne au sortir de la Seconde Guerre mondiale. Le Concordat de 1953 est un succès pour le régime puisque le Saint-Siège reconnaît et légitime en quelque sorte le franquisme aux yeux du monde entier. C'est à partir de là que l'Église assure des missions diplomatiques afin de réinsérer progressivement l'Espagne dans le concert des nations mondiales. Le Caudillo attend beaucoup des catholiques et, en retour, leur octroie des privilèges en particulier financiers.

«Des personnalités catholiques se voi[en]t confier des postes ministériels importants» ${ }^{64}$. Des figures issues de la Acción Católica Española telles que Joaquín Ruiz Giménez, Alberto Martín Artajo ou encore José Ibáñez Martín ont des responsabilités importantes dans le domaine politique. Et il n'en est pas moins vrai que les Ministères de la Justice et de l'Enseignement sont presque toujours confiés à des catholiques sous l'ère du général Franco. Le poids de l'Église dans le système éducatif est colossal : l'année scolaire 1940-1941 dans l'enseignement secondaire voit 104.005 élèves inscrits dans des établissements privés pour seulement 53.702 dans des établissements publics. Quantitativement, le privé attire deux fois plus d'élèves que le public dans les années 1940; les établissements privés vont attirer toujours plus d'élèves avec le temps, jusqu'à atteindre le chiffre de 241284 pour l'année scolaire 1960-1961, soit trois fois plus d'élèves que dans le public qui n'en accueille plus que 81 896 cette année-là ${ }^{6}$. L'enseignement religieux retrouve une place de choix dans ce

\footnotetext{
63 Pour lutter contre les dissensions internes, le Caudillo impose le Décret d'Unification (19 avril 1937) afin que les phalangistes et les traditionnalistes carlistes s'unissent. Manuel Hedilla et Lamberto de los Santos, deux membres importants de la Phalange, refusent cette union car elle est contraire aux idéaux du parti tels que l'entendait José Antonio Primo de Rivera, son fondateur. Ils sont condamnés à mort. Ces condamnations sont suivies par l'organisation immédiate de la Phalange Espagnole Authentique (le principal responsable, Juan Pérez de Cabo, est arrêté et condamné à mort en 1942). Après la guerre civile, le Movimiento Nacional - fusion entre la Falange Española Tradicionalista et les Juntas de Ofensiva Nacional Sindicalista constitue la branche politique de l'appareil d'État franquiste. La manœuvre a permis au général Franco d'écarter les phalangistes les plus radicaux. Il faut également noter que les phalangistes, dans leur immense majorité, étaient germanophiles et défendaient l'Allemagne nazie pendant la Seconde Guerre mondiale. Le ministre des Affaires Étrangères, Ramón Serrano Súñer, par ailleurs beau-frère du Caudillo, était même favorable à une entrée en guerre de l'Espagne aux côtés de l'Axe. La défaite de l'Axe en 1945 les discrédite réellement. Les bases nationalcatholiques sont plus solides que celles national-syndicalistes pour le régime. La fascisation de l'Espagne voulue par la Phalange s'arrête définitivement en 1945. Voir IMATZ, Arnaud, José Antonio, la Phalange espagnole et le national-syndicalisme, Paris, Godefroy de Bouillon, 2000; THOMÁS, Joan María, El gran golpe: el "caso Hedilla" o cómo Franco se quedó con Falange, Madrid, Debate, 2014.

64 BENNASSAR, Bartolomé, op. cit., p. 854.

65 PÉREZ AGOTE, Alfonso, «Sociología histórica del nacional-catolicismo español», cit. p. 223.
} 
nouveau dispositif que ce soit dans l'enseignement primaire ou dans l'enseignement secondaire, et même à l'Université, puisque le dogme et la morale chrétiennes sont reconnus comme les guides suprêmes de l'éducation. C'est ainsi que les enfants sont élevés et éduqués dans une ferveur catholique et finissent par constituer un véritable support idéologique au régime, ce qui garantit la permanence du système.

L'essor de l'Opus Dei, prélature personnelle de l'Église qui regroupe en son sein laïcs et prêtres, assoit encore davantage l'autorité du franquisme. Fondée en 1928 par le prêtre aragonais José María Escrivá de Balaguer, cette institution entend sanctifier le monde laïque et disséminer les valeurs spirituelles de l'Église à l'ensemble de la société. La formation élitiste et spirituelle de ses membres permet la conquête de postes clés : professeurs d'Université, hauts fonctionnaires, ou encore économistes. L'organisation de l'Opus Dei dont les débuts semblent modestes joue un rôle prépondérant dans le franquisme, plus particulièrement à partir des années 1960. C'est l'ère des technocrates, membres de l'Opus Dei, qui engagent une évolution en 1957, date charnière qui voit démarrer une nouvelle période du franquisme. L'équipe gouvernementale est remaniée: deux membres de l'Opus Dei intègrent la nouvelle composition du gouvernement, Mariano Navarro Rubio est investi aux Finances et Alberto Ullastres est nommé au Commerce. En 1962, Gregorio López Bravo rentre aussi au gouvernement, il est ministre de l'Industrie. Les membres de l'Opus Dei entendent libéraliser l'économie et l'ouvrir à l'extérieur dans une conjoncture internationale favorable ${ }^{66}$. Cette politique impulsée par l'Église a pour but de développer le pays. Ces hommes mettent en place un Plan de développement économique et la croissance est époustouflante à partir de 1960, si bien que les spécialistes nomment cette période «le miracle économique espagnol». L'Espagne connaît une ère de relative prospérité et découvre les modes de vie des pays qui l'entourent. Grâce à ce changement de politique économique, les habitants jouissent d'une amélioration considérable dans leur quotidien avec l'avènement de la société de consommation. Le régime compte alors sur ce relatif bien-être impulsé par les membres de l'Opus Dei pour ancrer encore davantage son régime. Dans une certaine mesure, l'Église est responsable de l'évolution et du progrès de l'Espagne. Face à l'immobilisme de l'Armée, l'Église joue une carte différente, celle de l'ouverture.

\footnotetext{
${ }^{66}$ Jusque-là, le franquisme avait souhaité se caractériser par l'autarcie de son régime, se voulant indépendant et autosuffisant... toutefois, l'échec économique et social criant de ces premières années du système le force à évoluer.
} 


\section{Conclusion}

Les deux institutions que sont l'Armée et l'Église semblent bel et bien être les clés de voûte du système franquiste. Victorieuses d'une longue et difficile guerre civile, elles appuient et légitiment le régime de par leur fidélité au dictateur, Francisco Franco. Le système franquiste est justifié de manière inconditionnelle par l'une et l'autre famille institutionnelle: l'Armée caractérise le déclenchement de la guerre civile d'Alzamiento nacional, nécessaire pour redresser le pays, en proie au désordre notamment à cause des communistes, des francs-maçons et des athées; l’Église parle d'une véritable croisade pour évoquer cette guerre fratricide et reconnaître l'entreprise nationaliste.

Entre 1939 et 1975, les piliers du régime vont assurer l'ordre à travers la peur de la répression exercée par l'Armée et la morale chrétienne prêchée par l'Église en activant chez chacun l'inquiétude du jugement dernier. Les outils utilisés par les clés de voûte du système sont efficaces : la détention, l'emprisonnement, l'exécution... pratiqués par l'Armée et l'enseignement catholique, la propagande... réalisés par l’Église; ce qui assure au franquisme une certaine longévité. La politisation des militaires et des clercs est également un facteur de stabilisation, l'Armée garantissant la sécurité du dictateur et de son régime sur le plan national et international, l'Église régissant l'éducation et la presse et se démarquant de par sa volonté de changement de politique économique dans les années 1960. Reconnaître le poids des militaires et des clercs dans l'assise du pouvoir franquiste est une évidence puisque les deux institutions permettent indéniablement à la dictature de durer et, plus encore, de s'ancrer dans l'histoire de l'Espagne: le Caudillo tient l'Espagne d'une main de fer pendant presqu'un demi siècle, il ne faut pas l'oublier. Les agissements de l'Armée et de l'Église dont la fiabilité est reconnue n'y sont point étrangers. Le rôle de ces deux institutions est donc, à tout le moins, double : d'une part, elles sont investies d'une fonction de légitimation de la dictature - de sa mise en place et de sa longévité - et, d'autre part, elles ont pour tâche de pérenniser et de stabiliser le régime du Caudillo autant que faire se peut. La mission est remplie. En ce sens, l'Armée et l'Église participent indéniablement à la pérennité et à la stabilité de la dictature franquiste.

Penser que tous les militaires et tous les clercs sont fidèles et attachés au régime franquiste est néanmoins un leurre. En effet, dans les années 1970, des voix d'opposition émanant de l'Armée et de l'Église commencent à se faire entendre. Bien que minoritaires, elles annoncent la fin du dictateur (le général Franco décède le 20 novembre 1975) et de son régime (qui s'effrite après la mort de Francisco Franco). La Unión Militar Democrática, organisation militaire clandestine fondée en 1974, tente de 
développer au sein de l'Armée des aspirations démocratiques. L'organisation est découverte par le régime l'année suivante. Certains membres sont alors déchus de leur fonction de militaire pour comportement déloyal. En ce qui concerne l'Église, l'opposition semble plus profonde puisque les intellectuels catholiques, au contact des courants démocratiques européens, commencent à amorcer un changement de politique économique à la fin des années 1950. La pensée libérale envahit certains clercs et membres de l'Opus Dei67. Dans les grandes villes espagnoles, les curés soutiennent les revendications ouvrières et créent deux organisations qui vont appuyer les réclamations des ouvriers: la HOAC, Hermandades Obreras de Acción Católica, et la JOC, Juventud Obrera Católica68. À la suite du Concile Vatican II (1962-1965), de nombreux curés accompagnés de jeunes catholiques participent à des manifestations antifranquistes, surtout en Catalogne et au Pays basque. Le pape Paul VI, hostile au franquisme, nomme alors de nouveaux évêques plus critiques, comme notamment le cardinal Vicente Enrique Tarancón. Des incidents se produisent au sein de l'Église et menacent le régime; c'est le cas par exemple de l'évêque Antonio Añoveros Ataún qui réclame la reconnaissance de l'identité et de la langue basque dans une pastorale. Ce dernier est menacé d'exil pour entrave à l'ordre public et à l'unité nationale de l'Espagne. En 1973, les évêques demandent la révision du Concordat et le respect de la liberté et de pluralité politique. Pour faire face aux revendications régionalistes et ouvrières de l'Église ${ }^{69}$, le franquisme crée une prison spéciale pour curés à Zamora, fait insolite dans un État catholique. Près d'une centaine de clercs passe par la prison de Zamora, incarcérée généralement pour des motifs politiques ou syndicaux.

${ }^{67}$ MONTERO GARCÍA, Feliciano, La Iglesia: de la colaboración a la disidencia (1956-1975), Madrid, Encuentro, 2009.

${ }^{68} \mathrm{La}$ distance prise entre l'Église et le régime franquiste se cristallise principalement dans des organisations qui sont sous la dépendance d'évêques espagnols. La Acción Católica Española, pionnière du changement, devient l'épicentre de l'autocritique catholique contre l'identification de l'Église et du franquisme. Cette prise de distance est progressive: elle débute dans les années 1950 et se renforce considérablement dans les années 1960, atteignant un climax au début des années 1970. Voir MONTERO GARCÍA, Feliciano, op. cit., pp. 64-78.

${ }^{69}$ Les curés qui soutiennent la cause nationaliste (notamment au Pays basque et en Catalogne) et la cause ouvrière sont nombreux. À la fin des années 1960, les messes dominicales de certains clercs dénoncent les pratiques du régime en place et se transforment parfois en véritables instigations à la révolte. 


\section{* L'auteur}

Justine Guitard est doctorante contractuelle à l'Université de Perpignan Via Domitia. Sa thèse porte sur la tauromachie et le régime franquiste, et plus précisément sur la figure de trois toreros majeurs, dont elle entend démontrer qu'à la fois ils incarnent les phases successives de la dictature, et qu'ils s'en écartent, à titre individuel, créant un véritable « appel d'air » dans celui, plus ou moins raréfié, du franquisme.

URL: < http://www.studistorici.com/progett/autori/\#Guitard >

\section{Per citare questo articolo:}

GUITARD, Justine, «Le poids des militaires et des clercs dans le pouvoir franquiste: un facteur de stabilité et de pérennité de la dictature?», Diacronie. Studi di Storia Contemporanea : Le dittature militari: fisionomia ed eredità politica, 29/12/2015,

URL:<http://www.studistorici.com/2015/12/29/guitard_numero_24/ >

Diacronie Studi di Storia Contemporanea $\beta$ www.diacronie.it

Risorsa digitale indipendente a carattere storiografico. Uscita trimestrale. redazione.diacronie@hotmail.it

Comitato di redazione: Jacopo Bassi - Luca Bufarale - Elisa Grandi - Antonio César Moreno Cantano - Deborah Paci - Fausto Pietrancosta - Alessandro Salvador - Matteo Tomasoni - Luca Zuccolo

Diritti: gli articoli di Diacronie. Studi di Storia Contemporanea sono pubblicati sotto licenza Creative Commons 3.0. Possono essere riprodotti e modificati a patto di indicare eventuali modifiche dei contenuti, di riconoscere la paternità dell'opera e di condividerla allo stesso modo. La citazione di estratti è comunque sempre autorizzata, nei limiti previsti dalla legge. 